Atmos. Chem. Phys., 13, 9713-9729, 2013

www.atmos-chem-phys.net/13/9713/2013/

doi:10.5194/acp-13-9713-2013

(c) Author(s) 2013. CC Attribution 3.0 License.

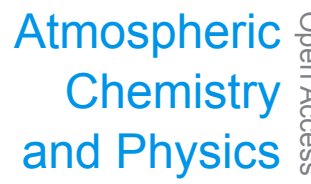

\title{
Climate and chemistry effects of a regional scale nuclear conflict
}

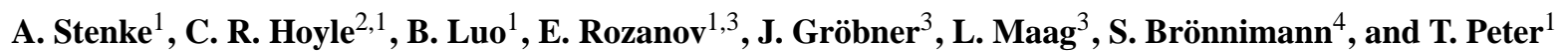 \\ ${ }^{1}$ Institute for Atmospheric and Climate Science, ETH Zurich, Switzerland \\ ${ }^{2}$ Laboratory of Atmospheric Chemistry, Paul Scherrer Institute, Villigen, Switzerland \\ ${ }^{3}$ Physical Meteorological Observatory (PMOD/WRC), Davos, Switzerland \\ ${ }^{4}$ Oeschger Centre for Climate Change Research and Institute of Geography, University of Bern, Bern, Switzerland \\ Correspondence to: A. Stenke (andrea.stenke@env.ethz.ch)
}

Received: 18 March 2013 - Published in Atmos. Chem. Phys. Discuss.: 8 May 2013

Revised: 23 August 2013 - Accepted: 30 August 2013 - Published: 2 October 2013

\begin{abstract}
Previous studies have highlighted the severity of detrimental effects for life on earth after an assumed regionally limited nuclear war. These effects are caused by climatic, chemical and radiative changes persisting for up to one decade. However, so far only a very limited number of climate model simulations have been performed, giving rise to the question how realistic previous computations have been. This study uses the coupled chemistry climate model (CCM) SOCOL, which belongs to a different family of CCMs than previously used, to investigate the consequences of such a hypothetical nuclear conflict. In accordance with previous studies, the present work assumes a scenario of a nuclear conflict between India and Pakistan, each applying 50 warheads with an individual blasting power of $15 \mathrm{kt}$ ("Hiroshima size") against the major population centers, resulting in the emission of tiny soot particles, which are generated in the firestorms expected in the aftermath of the detonations. Substantial uncertainties related to the calculation of likely soot emissions, particularly concerning assumptions of target fuel loading and targeting of weapons, have been addressed by simulating several scenarios, with soot emissions ranging from 1 to $12 \mathrm{Tg}$. Their high absorptivity with respect to solar radiation leads to a rapid self-lofting of the soot particles into the strato- and mesosphere within a few days after emission, where they remain for several years. Consequently, the model suggests earth's surface temperatures to drop by several degrees Celsius due to the shielding of solar irradiance by the soot, indicating a major global cooling. In addition, there is a substantial reduction of precipitation lasting 5 to $10 \mathrm{yr}$ after the conflict, depending on the magnitude of the initial soot release. Extreme cold spells associated with an increase in sea ice formation are found
\end{abstract}

during Northern Hemisphere winter, which expose the continental land masses of North America and Eurasia to a cooling of several degrees. In the stratosphere, the strong heating leads to an acceleration of catalytic ozone loss and, consequently, to enhancements of UV radiation at the ground. In contrast to surface temperature and precipitation changes, which show a linear dependence to the soot burden, there is a saturation effect with respect to stratospheric ozone chemistry. Soot emissions of $5 \mathrm{Tg}$ lead to an ozone column reduction of almost $50 \%$ in northern high latitudes, while emitting $12 \mathrm{Tg}$ only increases ozone loss by a further $10 \%$. In summary, this study, though using a different chemistry climate model, corroborates the previous investigations with respect to the atmospheric impacts. In addition to these persistent effects, the present study draws attention to episodically cold phases, which would likely add to the severity of human harm worldwide. The best insurance against such a catastrophic development would be the delegitimization of nuclear weapons.

\section{Introduction}

Recent studies by Robock et al. (2007b) and Mills et al. (2008) have shown that even a regionally limited nuclear war, for example between India and Pakistan, could have detrimental effects on climate and on the chemical composition of the atmosphere throughout the world. These investigations build on Toon et al. (2007), who assessed the amount of smoke emissions from urban firestroms after the detonation of relatively low-yield nuclear warheads in modern 
megacities. These soot particles would encounter rapid lifting into the upper troposphere due to pyro-convection (Toon et al., 2007), and would subsequently rise higher up into the stratosphere due to self-lofting (Robock et al., 2007b). Once in the stratosphere, these particles might induce long-lasting, global climate changes due to the shielding of solar radiation. There is evidence that these climatic changes could cause a significant decline in global food production, potentially triggering a famine of historic dimensions (Robock et al., 2007b; Xia and Robock, 2013). While Robock et al. (2007b) focused on climate effects, using the general circulation model (GCM) ModelE from NASA GISS coupled to a full ocean model, Mills et al. (2008) examined the consequences of the soot emissions for stratospheric chemistry and ozone, using the coupled chemistry-climate model WACCM3, but without an ocean model. The basic objective of the present study is to provide an independent estimate of the climate and chemistry effects of a regional nuclear war. To this end we apply the coupled chemistry-climate model SOCOL3, which is based on the atmospheric middle atmosphere version of the ECHAM5 GCM, coupled with a mixed-layer ocean model. By repeating the scenarios of the earlier studies, we aim to provide important information on the robustness of these previous results. The present study was carried out in two steps: (1) A SOCOL3 climate model run was performed, where the soot distribution in the atmosphere was prescribed to match the four dimensional (longitude, latitude, altitude, time) soot fields from the earlier chemistry climate model runs performed by Mills et al. (2008). (2) Several SOCOL3 runs were carried out, with different amounts of soot injected at the same location as in the study of Mills et al. (2008), and in which the soot particles were subsequently transported according to the simulated dynamical fields in a radiatively fully coupled manner. The rationale behind this two step approach was to evaluate the role of transport and radiative effects separately.

The following section provides a description of the applied soot emission scenarios. The model configuration and the experimental setup are described in Sect. 3. Section 4 presents the modeled soot distributions. Furthermore, the effects of the emitted soot particles on stratospheric and tropospheric temperatures, the hydrological cycle, and ozone chemistry are discussed. Concluding remarks are given in Sect. 5.

\section{Scenario}

Toon et al. (2007) assessed the potential damage and soot production of a regional nuclear conflict involving 100 Hiroshima-size $(15 \mathrm{kt})$ warheads. It was assumed that those low-yield weapons were targeted on city centers. To determine smoke emissions resulting from urban fires, Toon et al. (2007) used a direct relationship between the population density and the quantity of burnable fuel. Depending on the region and the involved nations, an attack on a single country
Table 1. Summary of assumed soot emission scenario (same as in Toon et al., 2007).

\begin{tabular}{ll}
\hline Geographic region & India vs. Pakistan \\
Number of warheads & 50 at $15 \mathrm{kt}$ each ("Hiroshima size") \\
Targeting & Main population centres attacked \\
Burnt area per bomb & $13 \mathrm{~km}^{2}$ (same as in Hiroshima) \\
Population density & 20000 persons km \\
Fuel loading & 11 tons person \\
Average soot emission factor & $0.016 \mathrm{~g}(\mathrm{soot})(\mathrm{g}(\mathrm{fuel}))^{-1}$ \\
Diameter of soot particles & $100 \mathrm{~nm}, 200 \mathrm{~nm}$
\end{tabular}

with 50 weapons of the above mentioned size could release between 1 and $5 \mathrm{Tg}$ of black carbon particles (soot) into the upper troposphere due to lofting by pyro-convection above large fires. The strong lofting of super-heated plumes has been confirmed using a three-dimensional cloud-scale model with interactive dynamics, microphysics, and radiative transfer, although a nested-grid mesoscale model would be desirable to close the gap between the large-scale transport, the plume-scale dynamics, and the smoke particle microphysics (E. J. Jensen, personal communication, 2013). For a regional conflict between India and Pakistan, Toon et al. (2007) derived an estimate of $\approx 6.6 \mathrm{Tg}$ of soot (their Table 13). Turco et al. (1990) and Toon et al. (2007) estimated an initial removal of soot in black rain in the range of $20 \%$, that is, about $80 \%$ of the emitted soot are lifted into the upper troposphere (150-300 hPa). This low rainout efficiency implies inefficient removal of small, fresh smoke particles in the pyrocumulus systems driven by an urban fire. Observations of such convection associated with forest fires (Fromm et al., 2005) support this notion. In addition to the initial removal in black rain, the model by Mills et al. (2008) calculated a further $20 \%$ loss of hydrophilic soot particles within the first days as the soot plume is lifted to the stratosphere. In contrast, Robock et al. (2007b) assumed that the soot particles are initially hydrophobic and, hence, did not calculate a significant initial loss of soot by black rain. The assumed scenario is summarized in Table 1.

There are many uncertainties in this scenario. For example, the estimated per capita fuel burden is based on surveys of fuel types and loadings per person in developed countries instead of developing nations. According to detailed estimates by Toon et al. (2007), the fuel loading in developing countries might be 2-3 times lower. Conversely, more weapons and/or larger yield weapons might be involved in such a conflict (P. Sidhu, personal communication, 2011). Toon et al. (2007) also assumed that only the most populous cities would be targeted, however, it is not clear if this would actually be the case. To deal with these uncertainties we performed several simulations with total soot emissions ranging from 1 to $12 \mathrm{Tg}$. The lower limit of $1 \mathrm{Tg}$ was also chosen to be comparable with the studies by Robock et al. (2007b) and Mills et al. (2008). Our $12 \mathrm{Tg}$ scenario is above the highest 
estimates by Toon et al. (2007) and was chosen to investigate potential saturation effects or tipping points.

\section{Model configuration and experimental setup}

\subsection{The chemistry-climate model SOCOL3}

The third generation of the coupled chemistry-climate model SOCOL (modeling tools for studies of SOlar Climate Ozone Links, Stenke et al., 2013) is based on the middle atmosphere version of the general circulation model MA-ECHAM5 (e.g., Roeckner et al., 2006; Manzini et al., 2006) and a modified version of the chemistry-transport model MEZON (Model for Evaluation of oZONe trends, Rozanov et al., 1999). The GCM and the chemistry module are interactively coupled via the 3-dimensional temperature field and the radiative forcing induced by water vapor, carbon dioxide, ozone, methane, nitrous oxide, and chlorofluorocarbons (CFCs). Water vapor, cloud variables and chemical species are advected by a flux-based mass-conserving and shape-preserving transport scheme (Lin and Rood, 1996). The chemistry scheme is called every $2 \mathrm{~h}$, making SOCOL computationally very efficient. The chemistry scheme incorporates a complete representation of stratospheric and mesospheric chemistry as well as a tropospheric background chemistry. The model includes 41 chemical species of the oxygen, hydrogen, nitrogen, carbon, chlorine and bromine groups, which are determined by 140 gas-phase reactions, 46 photolysis reactions and 16 heterogeneous reactions in/on aqueous sulfuric acid aerosols and three types of polar stratospheric clouds (PSC) (supercooled ternary solution (STS) droplets, water ice and nitric acid trihydrate (NAT)). Precalculated photolysis rates as functions of the ozone and oxygen amount, including effects of the solar irradiance variability, are used in a lookup table approach and interpolated to the actual ozone profile at every chemical time step (Rozanov et al., 1999). The effects of clouds on photolysis rates are parameterized according to Chang et al. (1987), the effects of aerosol particles, however, are not considered.

In the vertical dimension, the model has 39 levels, spanning the atmosphere from the surface up to $0.01 \mathrm{hPa}$ $(\sim 80 \mathrm{~km})$. For the present study the model was run at a spectral horizontal resolution of T42, which corresponds to a Gaussian transform grid size of approximately $2.8^{\circ} \times 2.8^{\circ}$. The dynamical time step is $5 \mathrm{~min}$. A detailed model description and evaluation of SOCOL3 is given by Stenke et al. (2013).

The atmospheric model is connected to a mixed-layer ocean (MLO) with a water column fixed depth of $50 \mathrm{~m}$ and a thermodynamic sea ice module. This model configuration does not consider active ocean dynamics, but captures the shorter term response of the ocean's surface temperature to the atmosphere. The heat budget of the oceanic mixed-layer is described by

$C_{\mathrm{m}} \frac{\partial T_{\mathrm{m}}}{\partial t}=H-Q$

where $T_{\mathrm{m}}$ denotes the temperature of the mixed-layer, which substitutes the sea surface temperature in the model version without ocean. $C_{\mathrm{m}}$ and $H$ describe the effective heat capacity of the mixed-layer and the net heat flux at the atmosphereocean surface, respectively. The oceanic heat transport $Q$ (also called flux correction term) is intended to compensate for the energy transport by ocean currents, which is not simulated by the MLO model itself (Steppuhn et al., 2006). The flux correction is calculated from a SOCOL simulation with prescribed sea surface temperatures representing present-day conditions.

It should be noted that the MLO (slab ocean) model does not include feedbacks with the deep ocean. However, Robock et al. (2007b) conducted several climate simulations with different soot emission scenarios using both a fully coupled ocean model and a MLO model, and found very similar results. In the mixed-layer simulations the cooling of the sea surface in the first year was found to be slower than in the full ocean model. The upper model layers of the full ocean model are thinner than in the MLO model and, therefore, respond more quickly to atmospheric perturbations. The further cooling in the mixed-layer model, however, was more pronounced and more persistent than in the full ocean model since the interaction with the deep ocean tends to dampen the surface response.

\subsection{Experimental setup}

With this model configuration, we conducted a $30 \mathrm{yr}$ timeslice control experiment without soot aerosol and several $10 \mathrm{yr}$ simulations including soot emissions, assuming present-day atmospheric conditions. Following Robock et al. (2007b) and Mills et al. (2008), we injected the soot in all simulations into a set of grid boxes at $30^{\circ} \mathrm{N}, 70^{\circ} \mathrm{E}$, that represent the upper troposphere between 300 and $150 \mathrm{hPa}$ above the India-Pakistan region, on 15 May. The assumed injection height mimics the lofting effect of strong pyro-convection over large fires within the first few hours of the detonations, which cannot be resolved by the global climate model. In total we performed a set of seven simulations with different soot emission scenarios. The total mass of emitted soot ranges between 1 and $12 \mathrm{Tg}$, addressing the uncertainties in the soot emission estimates described above. An overview of these model runs is given in Table 2.

To calculate the radiative effect of the soot burden, the optical properties (long-wave and shortwave absorption coefficients, single scattering albedos and extinctions) for a single soot particle with a diameter of either $100 \mathrm{~nm}$ or $200 \mathrm{~nm}$, respectively, were precalculated based on the wavelengthdependent refractive index (real and imaginary part) provided by the OPAC data set (Hess et al., 1998) using Mie 
Table 2. Summary of performed model simulations.

\begin{tabular}{lcc}
\hline Scenario & Soot mass $[\mathrm{Tg}]$ & Soot particle diameter $[\mathrm{nm}]$ \\
\hline CTRL & - & - \\
Prescribed & 5 & 100 \\
Exp1 & 1 & 100 \\
Exp2 & 2 & 100 \\
Exp5_100 & 5 & 100 \\
Exp5_200 & 5 & 200 \\
Exp7 & 7 & 100 \\
Exp12 & 12 & 100 \\
\hline
\end{tabular}

theory, and assuming a monodisperse population of soot particles. In the model simulations, these values were then scaled by the actual number density of soot particles.

As a first step, a $10 \mathrm{yr}$ model integration was performed, in which the 4-dimensional soot distribution simulated with the WACCM3 model (Mills et al., 2008) was used as input data for the SOCOL3 model (model experiment "Prescribed"). For that purpose the 4-D soot distribution was interpolated to the SOCOL3 grid and updated every transport time step. Within this model experiment, the prescribed soot caused a radiative forcing resulting in changes of atmospheric temperatures and circulation patterns, which will provide the first evidence whether the models are consistent with respect to their radiation scheme (in particular the heating rates). However, as the prescribed soot distribution follows WACCM3, it may be inconsistent with the simulated transport in SOCOL.

In a second step, we conducted a set of model simulations ("Exp1", ..., "Exp12"), in which the soot particles were freely transported according to the modeled circulation in SOCOL, that is, changes in atmospheric dynamics caused by the soot radiative forcing directly affected the transport of the soot particles. The simulation Exp5_200, where soot particles with a diameter of $200 \mathrm{~nm}$ instead of $100 \mathrm{~nm}$ as in the other simulations were used, serves as a sensitivity test to investigate the effects of the particle size on radiation and sedimentation. Since SOCOL does not include an aerosol module, the soot particles were treated like a gaseous trace species and transported with the operational advection scheme. In addition to the large-scale transport, sedimentation of the soot particles was calculated every time step. Tropospheric removal of soot by precipitation was also implemented, with the scavenging rate being set equal to that of $\mathrm{HNO}_{3}$ in SOCOL, which is generally represented as fully soluble in clouds and precipitation within atmospheric models. For $\mathrm{HNO}_{3}$ a constant removal rate of $4 \times 10^{6} \mathrm{~s}^{-1}$ is assumed, that is, every two hours $2.8 \%$ of the tropospheric $\mathrm{HNO}_{3}$ is removed. This implicitly assumes that soot particles in the troposphere readily acquire an inorganic coating. This approximation represents an upper bound for wet removal in the troposphere, which may result in an overall too rapid loss of soot in the very early days after the warhead detonations.
Furthermore, coagulation of the soot particles was not considered in the model simulations, because the impact of coagulation on stratospheric soot concentrations, and hence their lifetime and radiative effects, is expected to be small, given the small stratospheric particle densities of about $10^{-1} \mathrm{~cm}^{-3}$ (Robock et al., 2007b). In addition, coagulation of soot particles, if it occurs, leads to chain-shaped particles with sedimentation velocities similar to the unaggregated particles.

Deposition of soot particles on snow-covered surfaces and sea ice has the potential to decrease the albedo and partially compensate the surface cooling, a feedback effect that is not considered in the present model simulations. However, Vogelmann et al. (1992) showed that a sufficient amount of insolation and a correspondingly clean atmosphere would be necessary for this effect to become important. By the time the atmosphere would be clean enough again, fresh snow would have covered the deposited soot particles, and therefore this effect is expected to be small.

Our analysis is based on only one representation of each scenario, that is, ensemble runs were not considered. At least for the $>5 \mathrm{Tg}$ emission scenarios we expect that the model response to such a strong forcing is significantly larger than the natural variations of the chaotic weather system (Robock et al., 2007b).

Finally, it should be noted that the present study focuses only on the climatic and chemistry effects of the soot emissions. The spread of radionuclides and radioactive contamination are not part of this study.

\section{Results}

\subsection{Soot distribution}

The global atmospheric soot burden calculated by SOCOL, as a function of time, is shown in Fig. 1. Following the studies of Robock et al. (2007b) and Mills et al. (2008), the emission is assumed to take place on 15 May. For all of the runs, the burdens follow the same basic behavior, with a rapid loss of mass within the first 3-4 days of the emission, when the bulk of the soot is still in the troposphere (where wet scavenging by precipitation, the only loss mechanism accounted for, is active). Within the first 4 days, between $27 \%$ (Exp1) and 33\% (Exp12) of the soot is removed due to tropospheric rain out (Fig. 1a). Mills et al. (2008) simulated a slightly lower initial soot loss of approximately $19 \%$ for their $5 \mathrm{Tg}$ case, but as mentioned in Sect. 3.2, our wet removal procedure might be regarded as upper bound. The remaining aerosol particles are heated by the absorption of solar radiation, which in turn leads to a heating of the surrounding air and a rapid lofting of the soot particles into the stratosphere and higher. In Exp5, the soot particles are lofted up to the stratopause within 3 days, and reach the model top near $80 \mathrm{~km}$ after 5 days. It should be noted, though, that the vertical spreading of the bulk of the soot aerosol is 

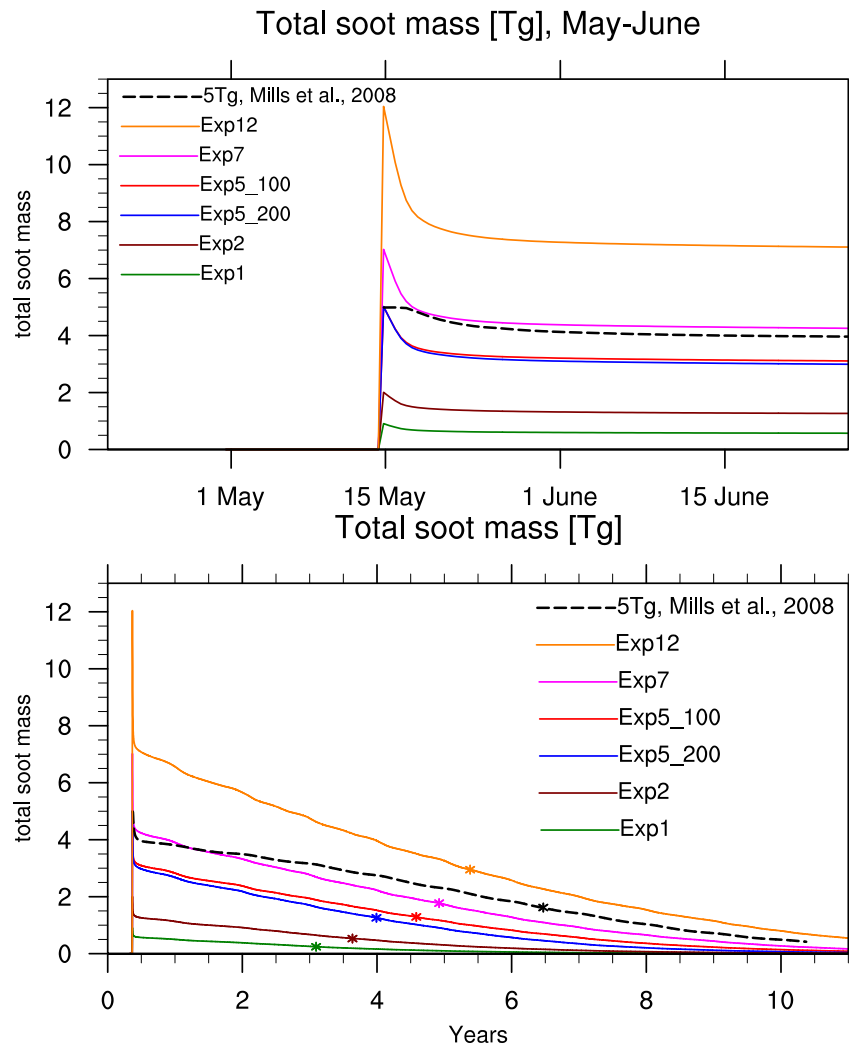

Fig. 1. Temporal evolution of the total mass of atmospheric soot for different amounts of soot initially emitted into the upper troposphere. The dashed black line indicates the results of Mills et al. (2008). The other lines show SOCOL results, including radiative feedback. Upper panel: first 45 days after soot emission. Lower panel: $11 \mathrm{yr}$ of simulation. The mass e-folding time of the atmospheric soot burden after the initial wash-out is indicated by stars.

not limited by the height of the model top. Figure 2 compares the vertical soot distribution for several scenarios after 15 days. Once transported into the stratosphere, the soot particles rapidly spread horizontally and are transported to the Southern Hemisphere. Further lofting is prevented by gravitational settling in the low ambient air density, keeping most of the particles below the stratopause. Mills et al. (2008) also simulated a maximum altitude of $80 \mathrm{~km}$ with the high-top model WACCM3 (model top at $4.5 \times 10^{-6} \mathrm{hPa}(\sim 145 \mathrm{~km})$ ). Overall, the soot distribution in SOCOL3 and the WACCM3 model, shown by Mills et al. (2008), look very similar, with WACCM3 showing less horizontal spreading.

Stratospheric soot particles have long residence times. The e-folding time of the atmospheric soot burden (after the initial rain out) ranges between $2.8 \mathrm{yr}$ for Exp1 and $5.1 \mathrm{yr}$ for Exp12 (Fig. 1b), which is shorter than in the studies of Robock et al. (2007b) (6 yr for the $5 \mathrm{Tg}$ case) and Mills et al. (2008), indicating a faster Brewer-Dobson Circulation in the SOCOL3 model, which is consistent with the general behavior found for ECHAM-based models in an international model intercomparison and validation initiative (CCMVal, 2010). The self-lofting effect of the emitted black carbon intensifies with the amount of initially emitted soot, that is, the more soot is emitted, the higher the fraction of soot transported high into the stratosphere and the longer the e-folding time. Saturation effects as found by Robock et al. (2007a) for a $150 \mathrm{Tg}$ case, representing conditions during a global nuclear war, where the complete blocking of sun light by soot particles higher up limits the lofting of further soot particles from lower down, are not visible in our model simulations for a regional conflict. The gravitational removal of the $200 \mathrm{~nm}$ soot particles in Exp5_200 is slightly faster than in Exp5_100, as expected, however the differences are small. Therefore, in this size range, the particle diameter is not critical for the atmospheric lifetime of the soot. The removal of these small, absorbing and thus heating particles is very slow, which highlights the general danger connected with emitting such particles to the stratosphere.

\subsection{Temperature changes}

In this section we focus on the heating of the stratosphere and mesosphere brought about by the absorption of solar radiation by the soot particles, and also on the cooling at the earth's surface, resulting from the reduced amounts of incoming radiation below the absorbing soot layer. As an example, Fig. 3 shows the soot optical depth for Exp5_100.

\subsubsection{Stratospheric and mesospheric heating}

Figure 4 shows the global mean atmospheric temperature change resulting from various soot emissions as a function of altitude and time. The temperature evolution of the prescribed experiment (Fig. 4b) is extremely similar to the results of Robock et al. (2007b, their Fig. 1c) as well as Mills et al. (2008, their Fig. 5c). From this plot, it is obvious that the soot has an almost immediate effect on the whole atmospheric column. In the very beginning of the simulation, the model shows a small cooling of the atmospheric layers above the soot cloud due to the blocking of outgoing infrared radiation. After 3 to 4 days, the soot has been transported to the top of the model atmosphere, and the resultant heating has caused an increase in atmospheric temperatures of $70-100 \mathrm{~K}$ between approximately $45-80 \mathrm{~km}$ altitude. Less heating occurs at lower altitudes because the soot prevents a part of the sunlight from reaching the lower altitudes. Below about $12 \mathrm{~km}$, average atmospheric temperatures are up to $3 \mathrm{~K}$ lower than in the control run due to the influence of the soot. Figure $4 \mathrm{c}$ shows the results from Exp5_100, that is, a free-running simulation with $5 \mathrm{Tg}$ soot emitted and conditions as assumed by Robock et al. (2007b). Despite the lower soot loadings shown in Fig. 1, the results are qualitatively very similar to those of Robock et al. (2007b), with initial heating of between $70 \mathrm{~K}$ and $100 \mathrm{~K}$ in the upper stratosphere and mesosphere, and heating of more 

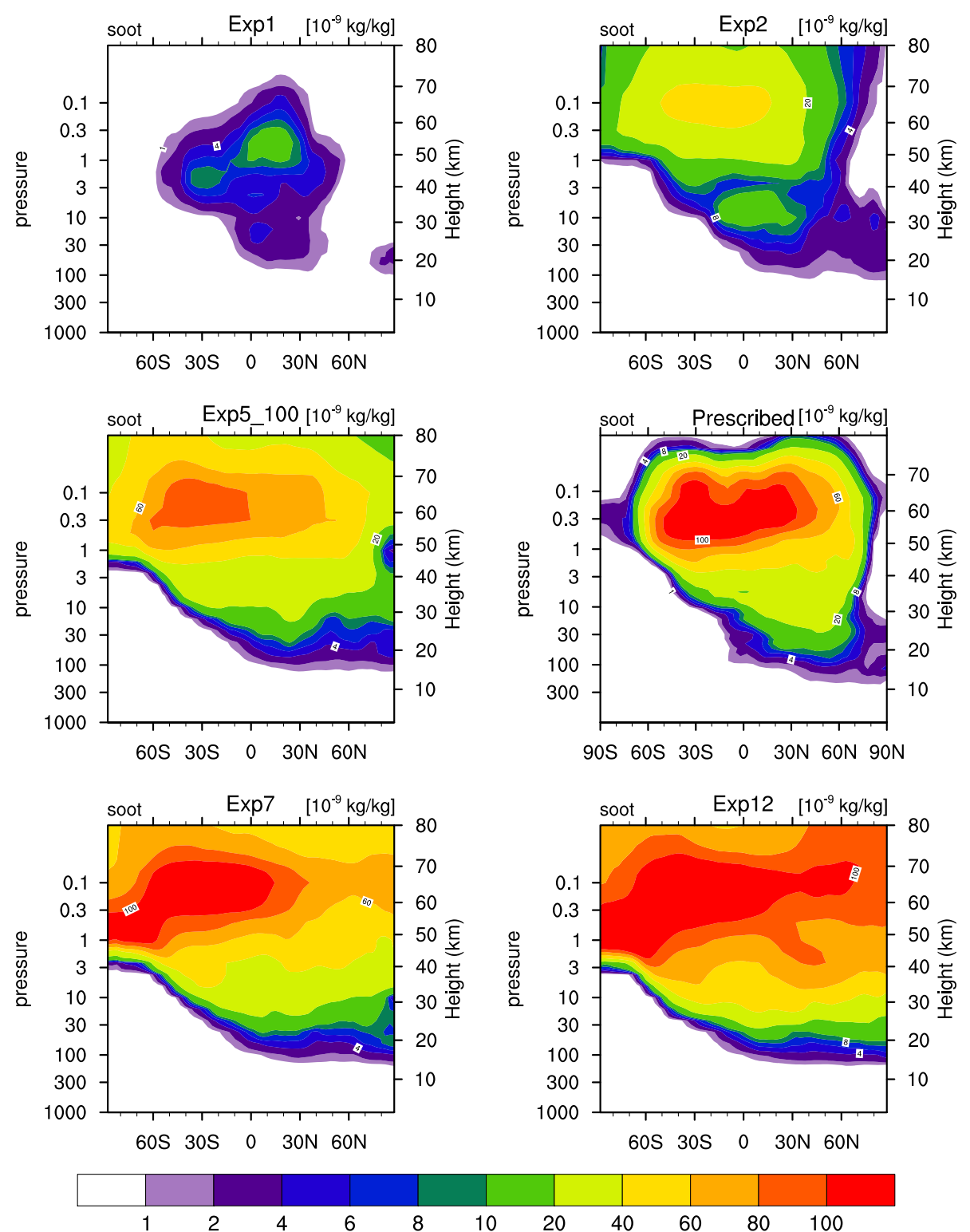

Fig. 2. Vertical soot distributions 15 days after the emission for various scenarios (Exp1, Exp2, Prescribed, Exp5_100, Exp7, Exp12). The distributions show the zonally averaged soot mass mixing ratio $\left[10^{-9} \mathrm{~kg} \mathrm{~kg}^{-1}\right]$ as function of latitude and altitude.

than $30 \mathrm{~K}$ lasting around one to two years at altitudes above approximately $30 \mathrm{~km}$. Again, the size assumed for the soot particles plays a minor role in determining the results, with runs Exp5_100 and Exp5_200 producing very similar atmospheric temperature changes, although the return to normal temperatures is slightly faster in Exp5_200 (not shown). As expected, the lower soot burdens in Exp1 (Fig. 4a) and Exp2 (not shown) result in substantially smaller stratospheric temperature changes. For Exp1, peak heating is of the order of $10-20 \mathrm{~K}$, and temperatures recover again after around three years. For model run Exp12 (Fig. 4d), a maximum temperature change of more than $110 \mathrm{~K}$ immediately after the soot injection is found, and even $10 \mathrm{yr}$ later stratospheric tempera- tures are still not back to normal conditions. The semiannual temperature oscillations in the upper stratosphere and mesosphere are related to a semiannual rising and sinking of the soot particles with the secondary meridional circulation during the solstice in each hemisphere (Robock et al., 2007b).

After 3 to $4 \mathrm{yr}$, depending on the soot scenario, the upper stratosphere and mesosphere both show a cooling signal, which is most pronounced in the uppermost model layers. This cooling is caused by a combination of different effects: Firstly, at the beginning, removal of soot particles from the mesosphere to lower altitudes via the Brewer-Dobson Circulation results in a reduced soot heating. As will be discussed in Sect. 4.5, the emitted soot leads to strong ozone depletion, 


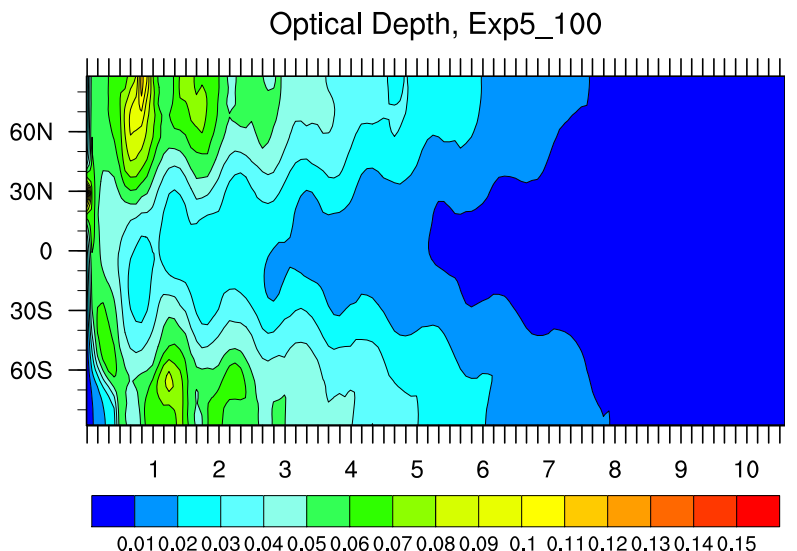

Fig. 3. Visible optical depth of soot particles for the Exp5_100 case as a function of latitude and time.

and, as a consequence, less shortwave heating. Finally, higher tropical tropopause temperatures cause a substantial increase in stratospheric and mesospheric water vapor concentrations (up to $+80 \%$ in Exp5_100 and up to $+200 \%$ in Exp12), which lead to a cooling due to increased radiative emission by the water vapor molecules. The occurrence of the maximum water vapor changes agrees with the maximum cooling, pointing to long-wave water vapor cooling as the dominant cause of the cooling.

\subsubsection{Global tropospheric cooling}

Due to the shielding of solar insolation by the emitted soot aerosols, global mean surface temperatures are subject to a more or less pronounced decrease, depending on emission scenario (Fig. 5, upper panel). For the $5 \mathrm{Tg}$ cases, peak surface temperature changes of about -1.0 to $-1.5 \mathrm{~K}$ appear about $3 \mathrm{yr}$ after the emission. Normal surface temperatures are approached only after approximately eight years. Again, the assumed particle size plays a minor role, with Exp5_100 and Exp5_200 producing very similar surface temperature changes. In contrast, when soot emissions are restricted to $1 \mathrm{Tg}$, there is no significant reduction in surface temperatures, with the deviation from the control run being within the bounds of normal variability. This lack in response in the surface temperatures is surprising at first sight. However, as the soot burden in the stratosphere is weaker by a factor of 4-5 in Exp1 compared to Exp5_100 (see Fig. 1), the blocking of sunlight arriving at the ground is lowered by approximately the same factor. This reduces the $1.0-1.5 \mathrm{~K}$ cooling in the $5 \mathrm{Tg}$ cases to only $0.2 \mathrm{~K}$, which is well within natural variability. To put this response into perspective: During the Little Ice Age (1500-1850), global average temperatures dropped about $0.5 \mathrm{~K}$ below normal conditions, and the Tambora eruption in 1815 (Indonesia), the largest volcanic eruption within the past $500 \mathrm{yr}$, also led to a global cooling of about $0.5 \mathrm{~K}$ for about one year.
The temperature change at the earth's surface averaged over the more densely populated latitudes of the Northern Hemisphere $\left(1.4\right.$ to $\left.60^{\circ} \mathrm{N}\right)$ as a function of time is illustrated in the lower panel of Fig. 5. The overall surface temperature changes are comparable to the global average, but an interesting set of features apparent in the northern hemispheric temperature changes are the regular, strongly negative temperature excursions in late winter and early spring (January to April), visible in all simulations except Exp1. For Exp12 temperature changes of up to $-4 \mathrm{~K}$ are simulated. Such conditions are reminiscent of the global war nuclear winter scenarios (Robock et al., 2007a).

\subsubsection{Regional cold spells}

Investigations of a potential nuclear famine following a regional nuclear war require knowledge of expected regional temperature changes. Figures 6 and 7 depict surface temperature changes averaged for June, July, and August, and for December, January, and February of the second year after the soot injection. Extensive cooling of several degrees over the continental land masses is clearly visible, that is, even a regionally limited nuclear war would have large global climatic impacts. As shown by Robock et al. (2007b) continental cooling together with precipitation and insolation changes shortens the length of the growing season (period with frost-free days) dramatically, in both hemispheres, for several years. For the first year, Robock et al. (2007b, their Fig. 11) calculated a reduction of the growing season of more than 20 days over large parts of the Northern Hemisphere. In comparison, old newspaper articles report that in 1816, the year without summer after the Tambora eruption, sweet corn did not ripen in a large area of the US East Coast (Hamilton, 1986), and Central Europe suffered from a high degree of starvation (Post, 1974). Growing season temperatures in 1816 were 1-3 K below average in large parts of Europe (e.g., Trigo et al., 2009; Auchmann et al., 2012). Exp5_100 shows temperatures reduced by up to $2 \mathrm{~K}$ in the American corn belt and reductions by up to $5 \mathrm{~K}$ in Central Europe during the growing season (Fig. 6).

Simulations Prescribed, Exp5_100, and Exp5_200 (not shown), although qualitatively similar, show differing temperature changes in some regions, for example, in the American Midwest, where the runs Prescribed and Exp5_200 produce a warming by $2 \mathrm{~K}$, whereas run Exp5_100 causes cooling. Given the similarity of these runs in terms of radiative forcing by the soot particles, these differences reflect the natural variability of the climate system in response to the aerosol forcing. Several model runs, with the exception of Exp12, indicate a warm response in Northern Eurasia in winter (Fig. 7), which is related to a strong positive mode of the Arctic Oscillation resulting in an advection of warm oceanic air masses over the winter continents (Robock et al., 2007b). This phenomenon is known from volcanic eruptions (Robock, 2000; Fischer et al., 2007). Table 3 compares 
a)

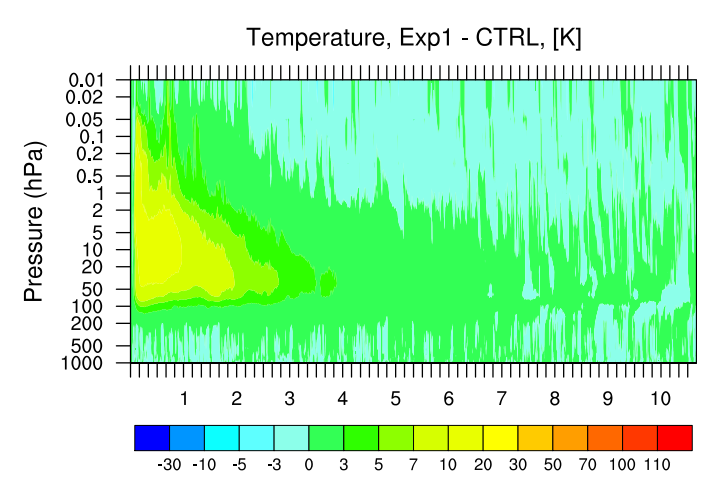

c)

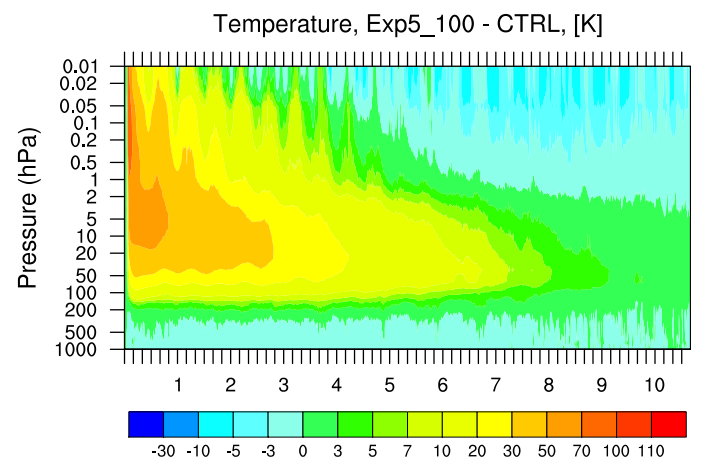

b)

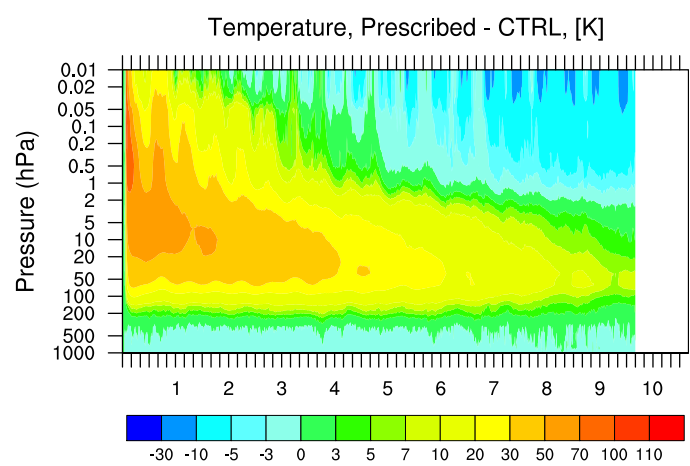

d)

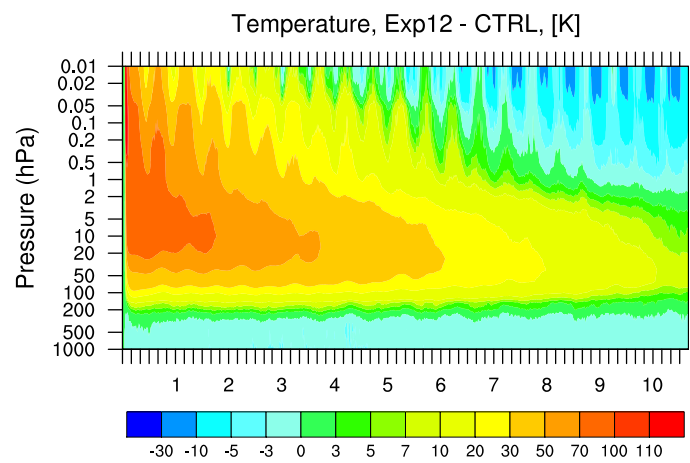

Fig. 4. Change in global mean temperature $[\mathrm{K}]$ as a function of altitude and time. (a) Exp1, (b) Prescribed run, (c) Exp5_100, (d) Exp12.

Table 3. Comparison of winter (DJF, first year) temperature changes for specific regions.

\begin{tabular}{lcc}
\hline Run & American corn belt & western Europe \\
\hline Robock et al. (2007b) & -1 to $-1.5^{\circ} \mathrm{C}$ & -1 to $-3^{\circ} \mathrm{C}$ \\
Prescribed & -3 to $-7^{\circ} \mathrm{C}$ & -1 to $-3^{\circ} \mathrm{C}$ \\
Exp5_100 & -3 to $-7^{\circ} \mathrm{C}$ & -3 to $-7^{\circ} \mathrm{C}$ \\
Exp5_200 & -5 to $-9^{\circ} \mathrm{C}$ & -1 to $-3^{\circ} \mathrm{C}$ \\
\hline
\end{tabular}

temperature changes during the first winter after the soot emission, for different regions, with results by Robock et al. (2007b, their Fig. 6). For the American corn belt SOCOL tends to simulate larger coolings, while both studies show similar results for western Europe. However, the comparison of regional changes is limited and has to be handled with care, since for SOCOL only one realization of each scenario run is available while Robock et al. (2007b) performed an ensemble of several model runs for each case. For a profound analysis of systematic differences between SOCOL and the model of Robock et al. (2007b) an ensemble of SOCOL runs would be necessary.

Another prominent feature apparent in the surface temperature changes for JJA is the warming pattern over large areas of Antarctica (Fig. 6). This warming is related to changes in the near-surface circulation pattern in southern mid- and high latitudes: while the control simulation shows zonal (westerly) winds that circle Antarctica, the soot runs are characterized by southerly flow over the southeastern Pacific, leading to the advection of warm air masses from low latitudes towards the region westwards of the Antarctic Peninsula.

\subsection{Sea ice coverage}

Figure 8 shows the time series of sea ice cover changes for the Northern and Southern Hemisphere. Both hemispheres reveal an earlier onset of sea ice formation in autumn as indicated by the peaks, as well as larger sea ice coverage throughout the year. Interestingly, the time series for the Southern Hemisphere shows unexpectedly small and large sea ice changes for all runs in year 4 and 10 after the soot emissions, respectively. These variations are related to an exceptional high and low sea ice coverage of the Weddell sea during the respective years in the CTRL simulation (not shown). This is a further example pointing to the limitations of having only one realization of each scenario. In the Northern Hemisphere the sea ice increase occurs mainly in the North Pacific between Kamchatka and Alaska (not shown). Smaller increases are also found in the North Atlantic south of Greenland. In the Southern Hemisphere the sea ice increase is most 

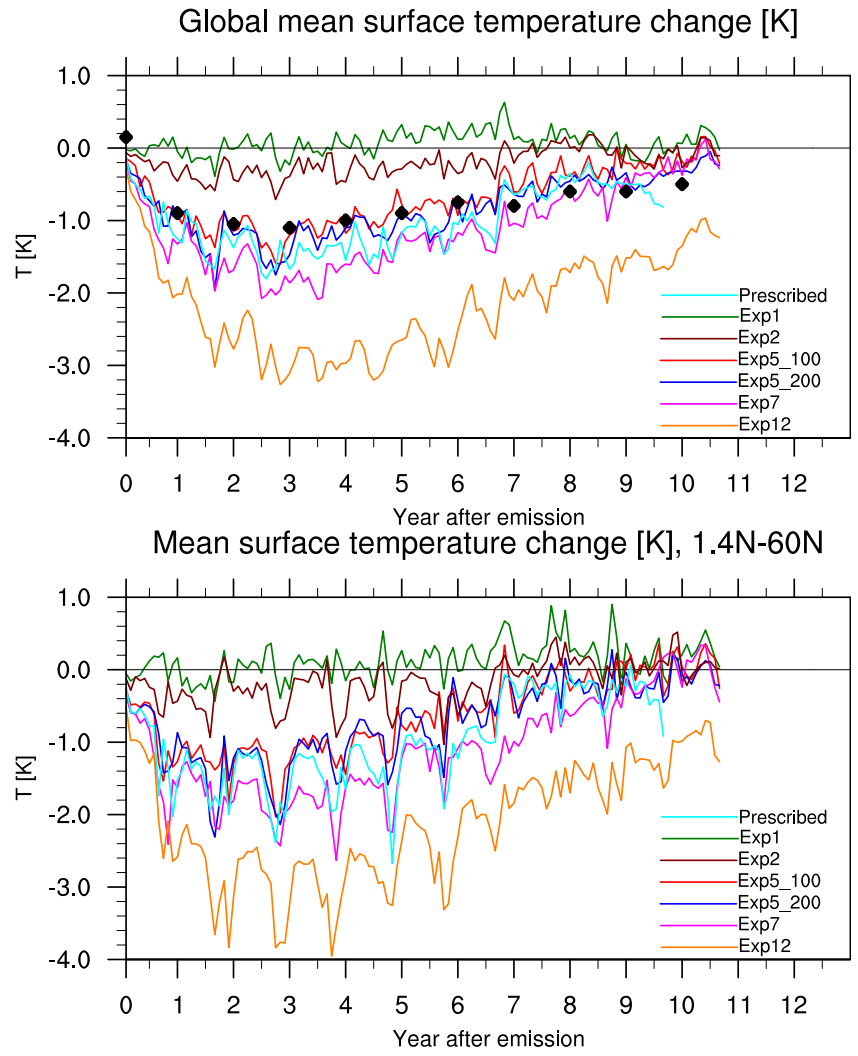

Fig. 5. Mean surface temperature changes $[\mathrm{K}]$ as function of time, globally averaged (upper panel) and averaged between $1.4^{\circ} \mathrm{N}$ and $60^{\circ} \mathrm{N}$ (lower panel). The black diamonds in the upper panel indicate the global mean temperature changes in May of each year for the 5 Tg case by Robock et al. (2007b, their Fig. 3).

pronounced in the southern Atlantic and Indian Ocean (not shown).

As mentioned in Sect. 3.1, the mixed-layer ocean model tends to simulate a more persistent cooling of the sea surface than a full ocean model (Robock et al., 2007b). Thus, one might speculate that the simulated sea ice response is also too pronounced and too persistent. Climate model simulations by Miller et al. (2012), together with proxy climate reconstructions, suggest that a series of explosive volcanic eruptions at a time of reduced solar irradiance triggered the onset of the Little Ice Age between 1275 and 1300 AD. The reduced solar insolation after the volcanic eruptions of up to $-30 \mathrm{Wm}^{-2}$ (Miller et al., 2012, their Fig. 3) caused an increase in Arctic sea ice volume of about $20 \%$, resulting in a self-sustaining sea ice/ocean feedback in the North Atlantic and persistent cold summers. For comparison, the decrease in solar insolation in Exp12 peaks at $-23 \mathrm{Wm}^{-2}$, associated with an increase in sea ice coverage of 30 to $40 \%$ in northern hemispheric winter. Stenchikov et al. (2009) investigated the seasonal to multidecadal response of the ocean to the eruption of Tambora in 1815 and Pinatubo in 1991 by using a coupled climate model, and found a sea ice response on a decadal timescale. For the Tambora case, which is comparable to the $5 \mathrm{Tg}$ cases in terms of reduced solar radiation at the surface, they found an increase in northern hemispheric maximum sea ice extent of $5 \%$. Interestingly, the minimum sea ice extent during the warm season showed a higher sensitivity to volcanic forcing than the maximum sea ice extent. Observational evidence for such model results is hardly available. Ships' logbooks provide at least some information about the years before and after the Tambora eruption. The period between 1810 and 1825 was characterised by consistently cold summers and large sea ice extent. However, records of Royal Navy expeditions to the Arctic show that in the Greenland Sea the summers of 1816 and 1817 were clearly warmer and showed less sea ice than the other years between 1810 and 1825 . Low sea ice coverage was also reported in Lancaster Sound in 1819 and 1820 (Brohan et al., 2010). Other ships' logbooks reported an exceptionally late sea ice dispersal in Hudson Bay and Hudson strait in summer 1816, with large impacts on shipping routes, and increased sea ice as far south as $40^{\circ} \mathrm{N}$, indicating unusual atmospheric circulation patterns over this region (Catchpole and Faurer, 1985). The mentioned modeling studies and observational reports of sea ice responses to volcanic clouds indicate that the persistence of the sea ice response as simulated with the mixed-layer ocean model is indeed reasonable. However, the comparison with the results of Miller et al. (2012) suggests that the simulated sea ice increase might be overestimated.

\subsection{Precipitation changes}

The cooling of the earth's surface leads to a reduced evapotranspiration and a weakening of the global hydrological cycle. The global averaged changes in precipitation are shown in Fig. 9. The largest changes in global precipitation occur between 2 and $4 \mathrm{yr}$ after the soot injection for the runs with soot loadings of $5 \mathrm{Tg}$ or larger, following the temperature changes at the surface (Fig. 5). For the $5 \mathrm{Tg}$ simulations, precipitation is reduced by up to $10 \%$ (Fig. 10), which is in excellent agreement with Robock et al. $(2007 \mathrm{~b}$, their Fig. 3). In the $12 \mathrm{Tg}$ run, precipitation is reduced by up to $20 \%$ (Fig. 10). For the low emission scenarios, Exp1 and Exp2, global precipitation changes are below $5 \%$. In both of these two simulations, the hydrological cycle quickly returns to normal conditions, while it takes 8 to $10 \mathrm{yr}$ for the medium scenarios, and up to 14 years for Exp12 (not shown). The weakening of the global hydrological cycle increases almost linearly with the initial soot burden (Fig. 10), that is, our model simulations do not indicate any saturation effects such as those found by Robock et al. (2007a) for soot injections of $50 \mathrm{Tg}$ and $150 \mathrm{Tg}$.

Figures 11 and 12 show maps of precipitation changes averaged for June, July, and August, and for December, January, and February of the second year after the soot injection. The change patterns are very similar for all soot emission scenarios. The most pronounced changes occur in the 

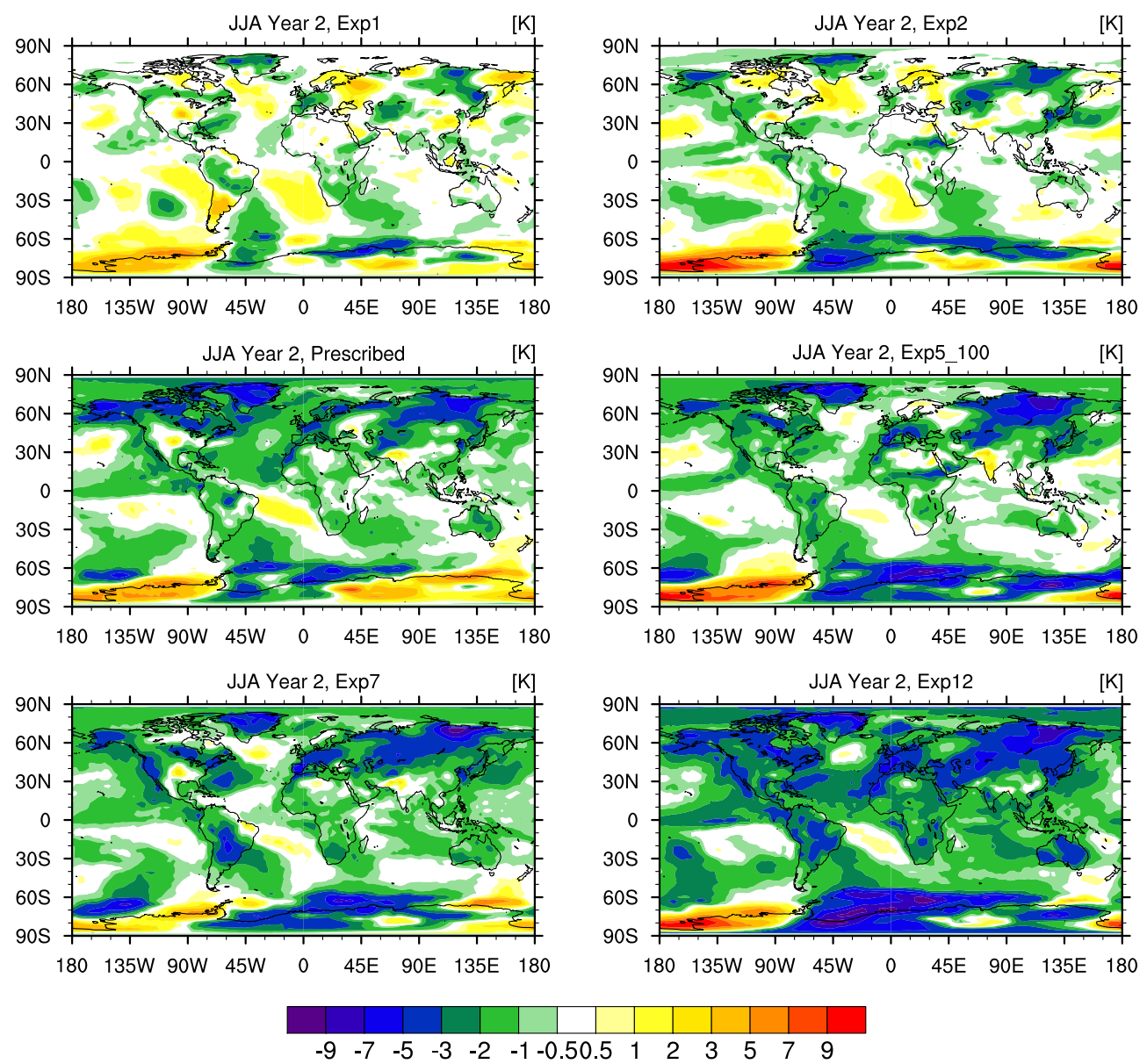

Fig. 6. Surface temperature changes $[\mathrm{K}]$ averaged for June, July, and August of the second year following the soot injection for Exp1, Exp2, Prescribed, Exp5_100, Exp7, and Exp12.

Intertropical Convergence Zone (ITCZ). Further substantial changes are found over the Asian region, showing a weakening of the summer monsoon (Fig. 11). In contrast to Robock et al. (2007b), our model simulations do not indicate an increase of precipitation over the Sahel zone of Africa. Robock et al. (2007b) interpreted these changes as a weakening of the Hadley Cell. A weakening of the Asian summer monsoon circulation is also found after major tropical volcanic eruptions in model simulations (Joseph and Zeng, 2011) and treering-based reconstructions (Anchukaitis et al., 2010). This change in summer monsoon is interpreted as a consequence of the weaker land-sea thermal contrast (Joseph and Zeng, 2011).

\subsection{Ozone loss and UV changes}

The increase in stratospheric temperatures, caused by the soot, lead to the acceleration of chemical reaction cycles leading to ozone loss, as described by Mills et al. (2008). Furthermore, higher temperatures at the tropical tropopause and an enhanced methane oxidation result in substantially increased stratospheric water vapor concentrations, which leads to additional ozone loss. In Exp1, lower stratospheric water vapor increases by up to 50\%, in Exp5_100 lower stratospheric $\mathrm{H}_{2} \mathrm{O}$ more than doubles (not shown). The changes in total column ozone in the soot experiments with respect to the control run are shown in Fig. 13. At low latitudes there are no significant ozone changes for the two low soot cases, Exp1 and Exp2, while for the $5 \mathrm{Tg}$ simulations the ozone loss is around 5-10\%, and the initial recovery sets in after around $5 \mathrm{yr}$. Exp7 and Exp12 show tropical ozone reductions of up to $30 \%$. At higher latitudes, ozone loss is more pronounced. The mid-range $(5 \mathrm{Tg})$ scenarios show 40 to $60 \%$ less total ozone polewards of $60^{\circ}$. Peak values of up to $-70 \%$ are found in polar regions for the first $5 \mathrm{yr}$ of Exp12. Globally, in the two years following the soot emissions, ozone is very low, approaching levels of around $220 \mathrm{DU}$ for the 5,7 , and $12 \mathrm{Tg}$ simulations, which are levels typically associated with ozone hole conditions (Fig. 14). The annual mean, global mean total ozone loss for the second year ranges between $5 \%(\operatorname{Exp} 1)$ and $28 \%$ (Exp12), which is much more than the 2002-2009 global mean total ozone 

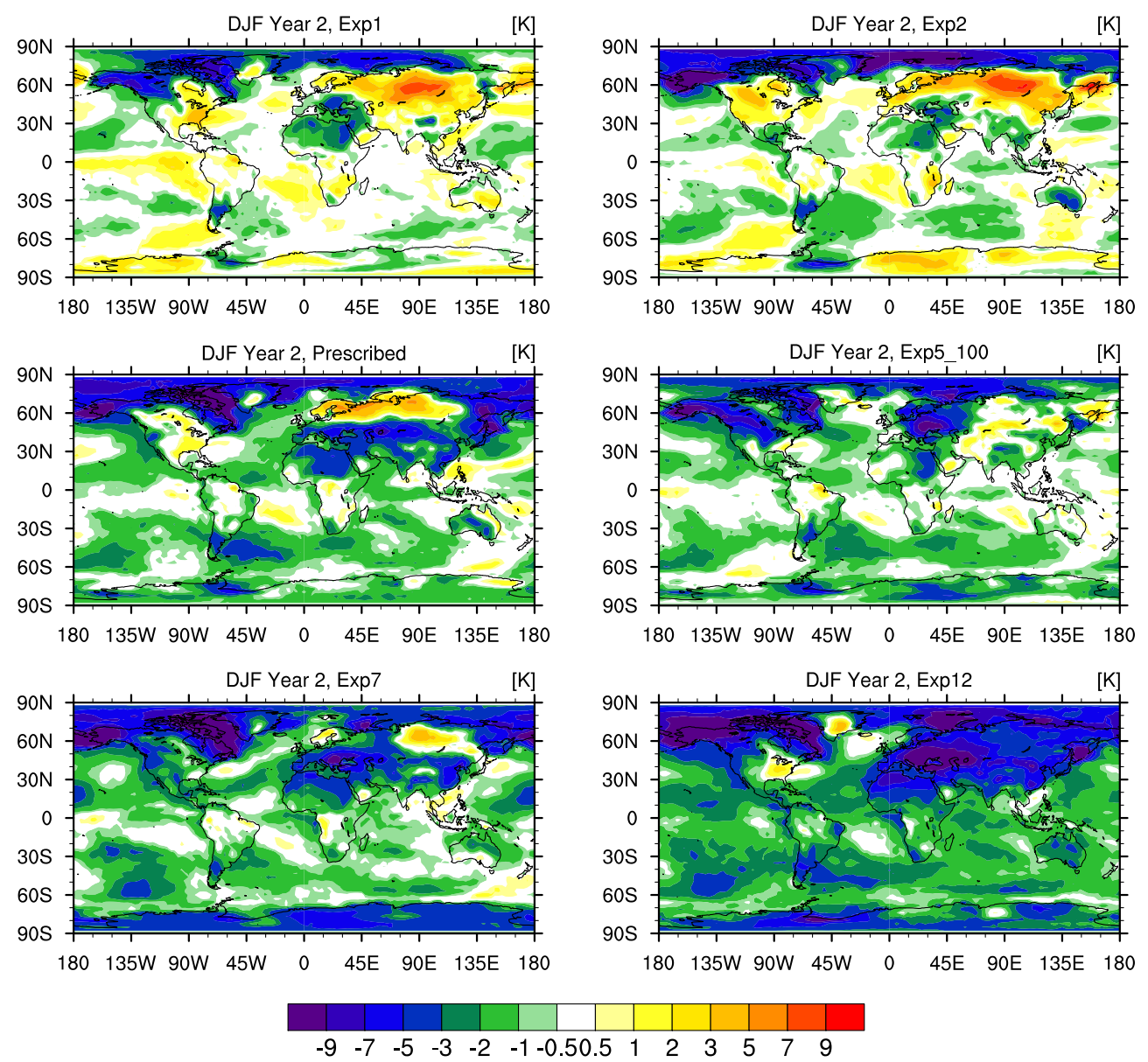

Fig. 7. Same as Fig. 6, but averaged for December, January, and February of the second year.

loss of $3.5 \%$ (relative to 1964-1980 averages) due to anthropogenic ODS emissions (Douglass et al., 2011). As may be expected, the ozone loss increases with the atmospheric soot burden. In contrast to the surface temperature and precipitation changes, there is a saturation effect with respect to total column ozone losses. For the emission scenarios of more than $2 \mathrm{Tg}$, additional soot mass leads to progressively less of an additional $\mathrm{O}_{3}$ loss. In northern mid- to high latitudes, the prescribed soot leads to almost similar total ozone values as the $12 \mathrm{Tg}$ case. The black dashed line in Fig. 14 shows results for the $5 \mathrm{Tg}$ case by Mills et al. (2008) for comparison. At southern high latitudes their total column ozone is as low as in Exp12, however, total column ozone in this region is generally lower in WACCM3 than in SOCOL (compare Mills et al., 2008, their Fig. 3).

The strong warming of the stratosphere has a direct impact on chemical reactions rates. Mills et al. (2008) identified the Chapman (odd-oxygen) and the odd-nitrogen cycles as mainly responsible for the ozone loss after the soot injection. Both cycles are highly temperature dependent and become faster with increasing temperatures $\left(k_{\mathrm{O}+\mathrm{O}_{3}}=\right.$ $8 \times 10^{-12} \cdot \exp \left(-2.060 \times 10^{3} \cdot T^{-1}\right), k_{\mathrm{NO}_{2}+\mathrm{O}}=5.1 \times 10^{-12}$. $\left.\exp \left(2.1 \times 10^{2} \cdot T^{-1}\right)\right)$; however, the rate of increase of the $\mathrm{NO}_{\mathrm{x}}$ loss cycle decelerates with higher temperatures. Furthermore, as also mentioned by Mills et al. (2008), the depletion of ozone triggers a "self-healing" effect associated with more UV radiation penetrating deeper into the atmosphere and an enhanced photolysis of $\mathrm{O}_{2}$, which partly compensates the ozone loss. It should be noted that the radiative impact of the soot particles on the photolysis rates was not considered in the model simulations (see Sect. 3.1).

As obvious from Fig. 13, all simulations show an increase in tropical total ozone. For simulations with more than $2 \mathrm{Tg}$ of soot emissions, this increase takes place in the second half of the simulation. This is related to an ozone increase in the tropical uppermost troposphere and lower stratosphere caused by the deeper penetration of UV radiation in the atmosphere and a shift of $\mathrm{NO}$ into $\mathrm{NO}_{2}$ via the reactions with $\mathrm{HO}_{2}$ and $\mathrm{CH}_{3} \mathrm{O}_{2}$. For the simulations with more than $2 \mathrm{Tg}$ of soot emissions, ozone loss in atmospheric levels above approximately $30 \mathrm{hPa}$ dominates the ozone column in the first years of the simulation. Later on, enhanced ozone levels in the lower stratosphere overcompensate the diminishing ozone depletion higher up. 

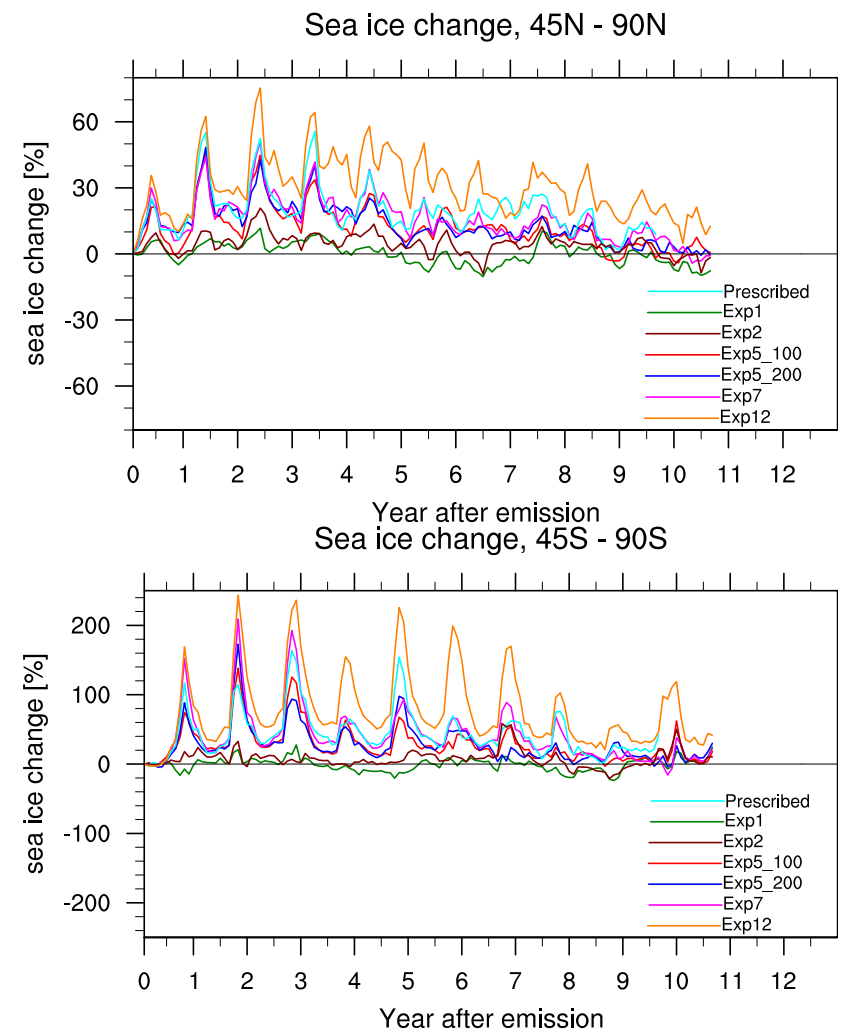

Fig. 8. Changes in total sea ice coverage [\%] for the latitude band 45 to $90^{\circ} \mathrm{N}$ (upper panel), and 45 to $90^{\circ} \mathrm{S}$ (lower panel) as function of time.

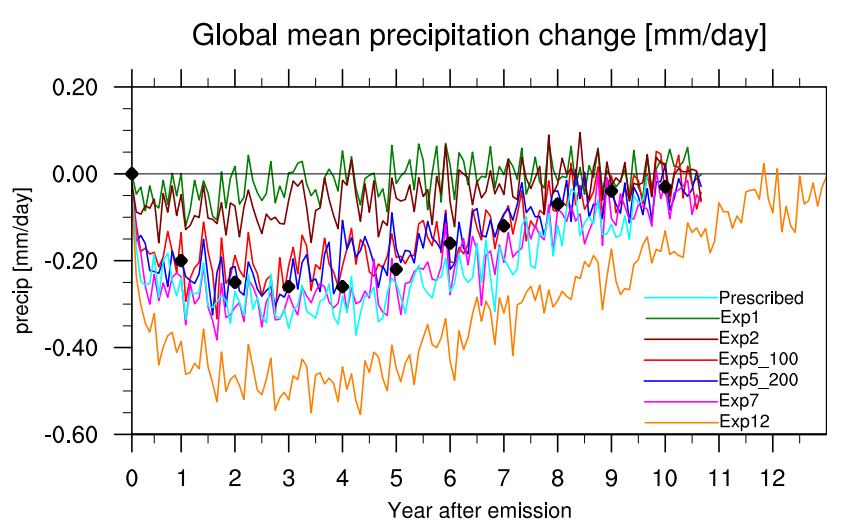

Fig. 9. Global mean precipitation changes $\left[\mathrm{mmday}^{-1}\right]$ as function of time. The black diamonds in the upper panel indicate the global mean precipitation changes in May of each year for the $5 \mathrm{Tg}$ case by Robock et al. (2007b, their Fig. 3).

The ozone loss affects the amount of solar UV radiation reaching the earth's surface. The spectral surface ultraviolet radiation in the wavelength range 280 to $400 \mathrm{~nm}$ was calculated with the radiative transfer model libRadTran (Mayer and Kylling, 2005), using the vertical profiles of ozone mixing ratio and soot particle concentrations, which are the most significant variables affecting the radiation transfer through
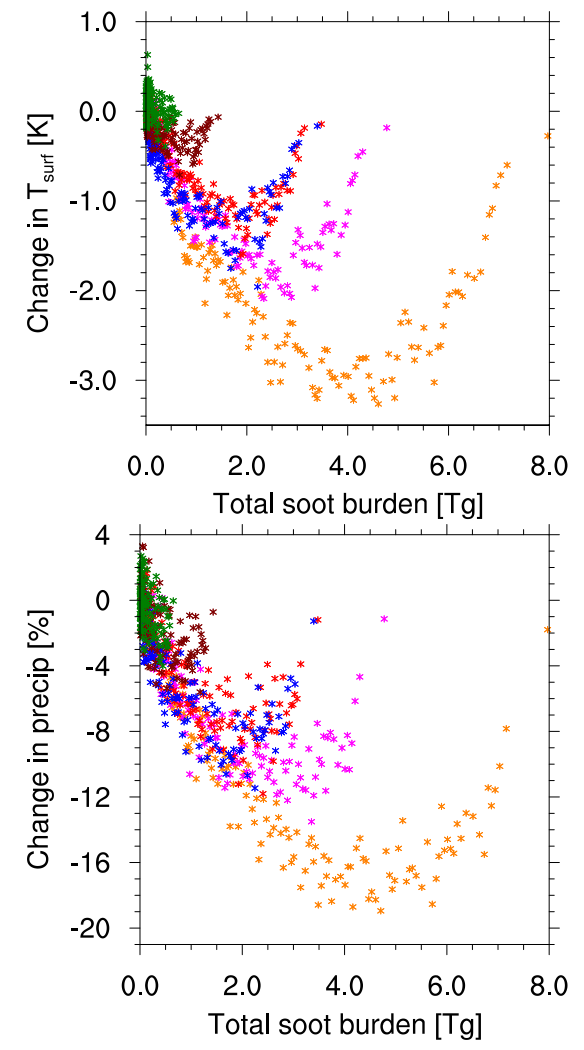

Fig. 10. Evolution of global mean temperature $[\mathrm{K}]$ (left) and precipitation changes $\left[\mathrm{mm} \mathrm{day}^{-1}\right.$ ] (right) as function of total soot burden [Tg], for Exp1 (green), Exp2 (brown), Exp5_100 (red), Exp5_200 (blue), Exp7 (magenta) and Exp12 (orange).

the atmosphere. For the soot particles, the scattering and extinction properties were calculated using MIE code from libRadTran assuming that they consist of pure carbon and have a fixed size of $100 \mathrm{~nm}$ as described in a previous section. Due to the extensive computing time, the calculations were limited to the CTRL and Exp5_100 runs for the first five and a half years of the experiment. Figure 15 shows the zonally averaged erythemally weighted (sunburning) radiation change with respect to the control run. The white areas in the figure at high latitudes correspond to times when the sun has not risen above the horizon and therefore no solar radiation reaches the earth's surface. As expected, there is a good correlation between the UV radiation and the ozone losses shown in Fig. 13, with UV radiation in summer being up to $50 \%$ higher than in the control run. The smallest changes are seen in the latitudinal band between $20^{\circ} \mathrm{N}$ and $20^{\circ} \mathrm{S}$, where changes in UV are less than $10 \%$ and a recovery is already achieved by the end of the second year. Most noteworthy is the situation at middle latitudes, around 40 to $60^{\circ}$. As can be seen from the figure, the UV enhancements during the summer months are up to $40 \%$ relative to the control run, indicating high UV levels with significant adverse effects on human 

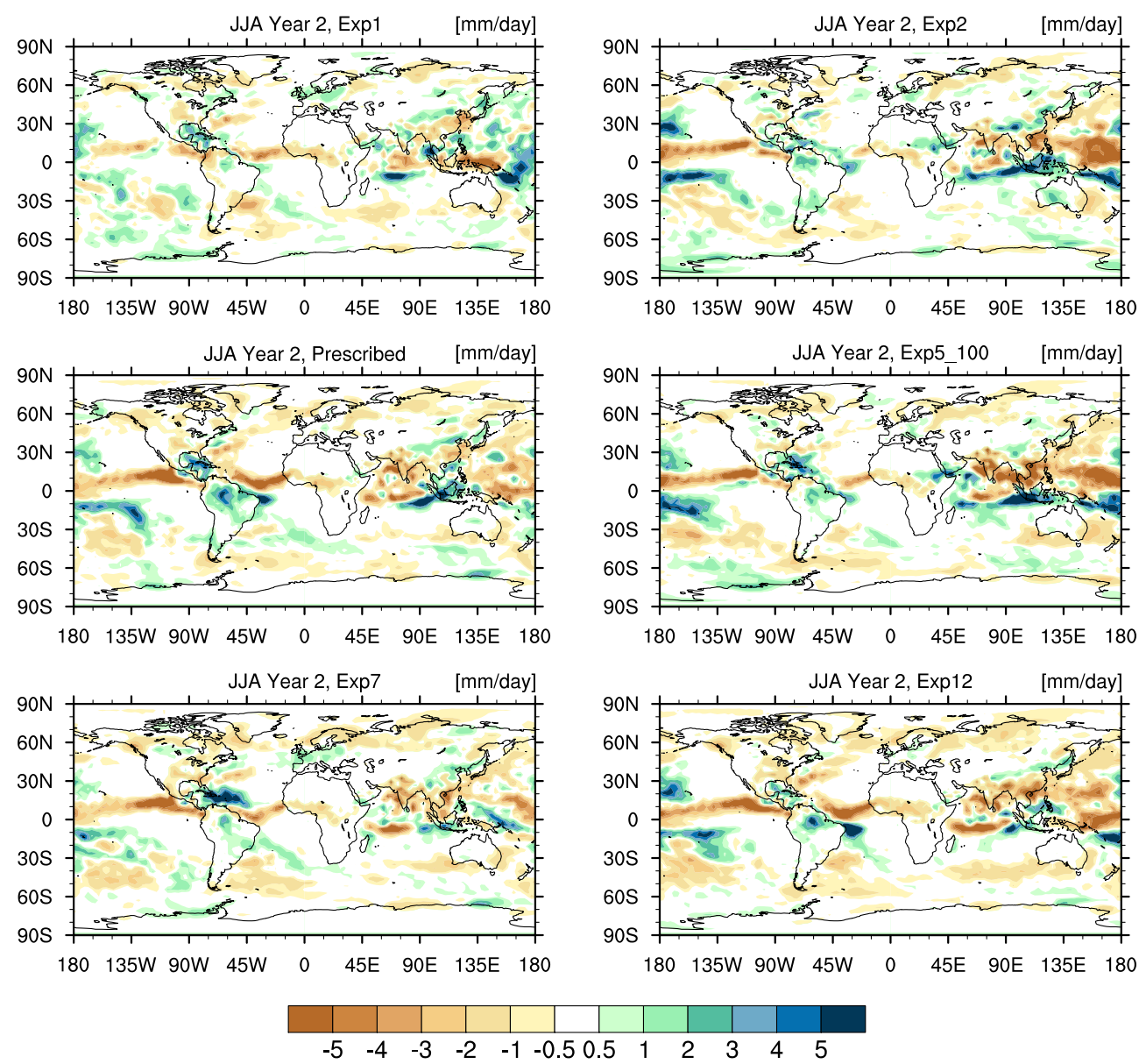

Fig. 11. Precipitation changes [mmday ${ }^{-1}$ ] averaged for June, July, and August of the second year following the soot injection for Exp1, Exp2, Prescribed, Exp5_100, Exp7, and Exp12.

health, plants and the biosphere in general. At latitudes above $60^{\circ}$, these summer increases can reach $50 \%$.

Interestingly, one at first sight contradictory picture is observed during the first $4 \mathrm{yr}$ in the winter months at latitudes above $60^{\circ}$. While ozone levels remain below those of the control run, the UV levels are also lower than in the control run. Indeed, soot particles are absorbing a significant part of the solar UV radiation due to the long slant path through the atmosphere, overcompensating the missing ozone in the atmosphere. This behavior is less pronounced in the Southern Hemisphere, where less soot is deposited at high latitudes. Furthermore, this effect gradually diminishes as the soot particles are removed from the atmosphere. While lower UV levels are generally seen as beneficial, in wintertime at middle to high latitudes they also lead to a reduced ability of the body to produce vitamin $\mathrm{D}$, which is essential to human health (Holick, 2004).

The overall situation for UV radiation is remarkable. While for most of the year UV levels have dramatically increased due to the depleted total ozone, the UV levels in the wintertime are significantly reduced by up to $30 \%$ when they are actually most needed for vitamin $\mathrm{D}$ production. The overall conclusion is that while the soot particles are not able to compensate the large ozone losses in the summer months, they overcompensate the ozone losses in winter, leading to reduced UV levels and therefore exacerbating the vitamin D problem in this period of the year (Webb and Engelson, 2006).

\section{Discussion and conclusions}

The model simulations presented here largely confirm the results presented in Mills et al. (2008) and Robock et al. (2007b). When we prescribe the soot fields provided by Mills et al. (2008) in the SOCOL3 model, the atmospheric heating found by Mills et al. (2008) is almost exactly reproduced. This indicates that both models, SOCOL3 and WACCM3, calculate similar radiative effects of the soot. When SOCOL3 is allowed to transport the soot independently, the initial reduction of the mass of soot in the first days and weeks of the simulation is larger than in Mills et al. (2008). This is most likely due to differences in the applied parameterizations of 

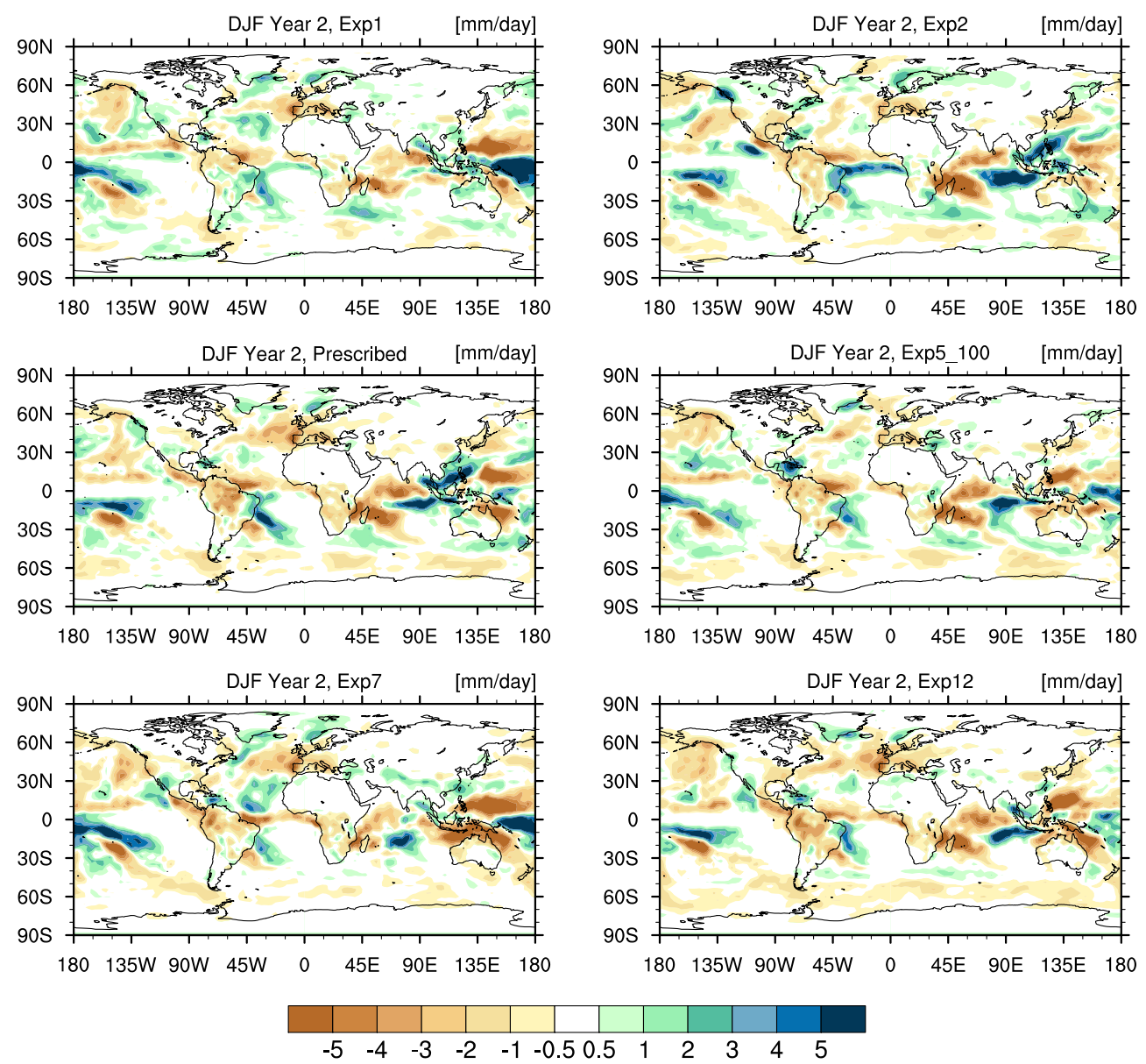

Fig. 12. Same as Fig. 11, but averaged for December, January, and February of the second year.

wet soot removal. Nevertheless, the simulated atmospheric heating, ozone loss, and recovery times are still similar to that found by Mills et al. (2008), despite the slightly lower soot burden. A further $5 \mathrm{Tg}$ model run with a particle diameter of $200 \mathrm{~nm}$ rather than $100 \mathrm{~nm}$ led to a slightly faster removal of soot from the atmosphere. However, temperature changes and ozone loss were largely unaffected by this doubling of the particle size.

There are substantial uncertainties in the calculation of the likely soot emissions (Toon et al., 2007), particularly in the assumptions regarding fuel loadings and the targeting of weapons. While the fuel loadings are calculated based on western cities, where the data for such calculations is more readily available, it is not clear exactly how different the loadings are in other countries. Further, reduced soot emissions may come about as military targets are included in the attack, rather than only the most populated areas. To deal with these uncertainties we performed several model runs with soot emissions ranging from 1 to $12 \mathrm{Tg}$. In the $1 \mathrm{Tg}$ case, atmospheric heating and the surface cooling is greatly reduced, but the effects of the soot on atmospheric ozone are still obvious. The cooling of the earth's surface is accompa- nied by a severe reduction in global precipitation of up to $20 \%$ for the $12 \mathrm{Tg}$ case. While surface temperature and precipitation changes scale almost linearly with the soot burden, at least within the range of our emission scenarios, simulated ozone losses show a saturation effect, which is on the one hand related to a non-linear temperature dependence of the relevant chemical reaction rates, and on the other hand to a "self-healing" effect of stratospheric ozone.

A further interesting result of the present simulations is the strong increase in sea ice coverage over both hemispheres. Ice feedback effects are expected to prolong and enhance the climatic response to the soot emissions. Robock et al. (2007b) did not report similar sea ice increases in their model simulations. A prolonged sea ice coverage could have strong impact on shipping routes and, for example, global food and fuel supply, especially in the Northern Hemisphere.

The climatic effects of soot injections from firestorms after a nuclear conflict are similar to those after large volcanic eruptions (for a review article on climatic effects of volcanic eruptions see Robock, 2000, and references therein), which inject large amounts of sulfur into the atmosphere. In both cases the additional stratospheric aerosol leads to 

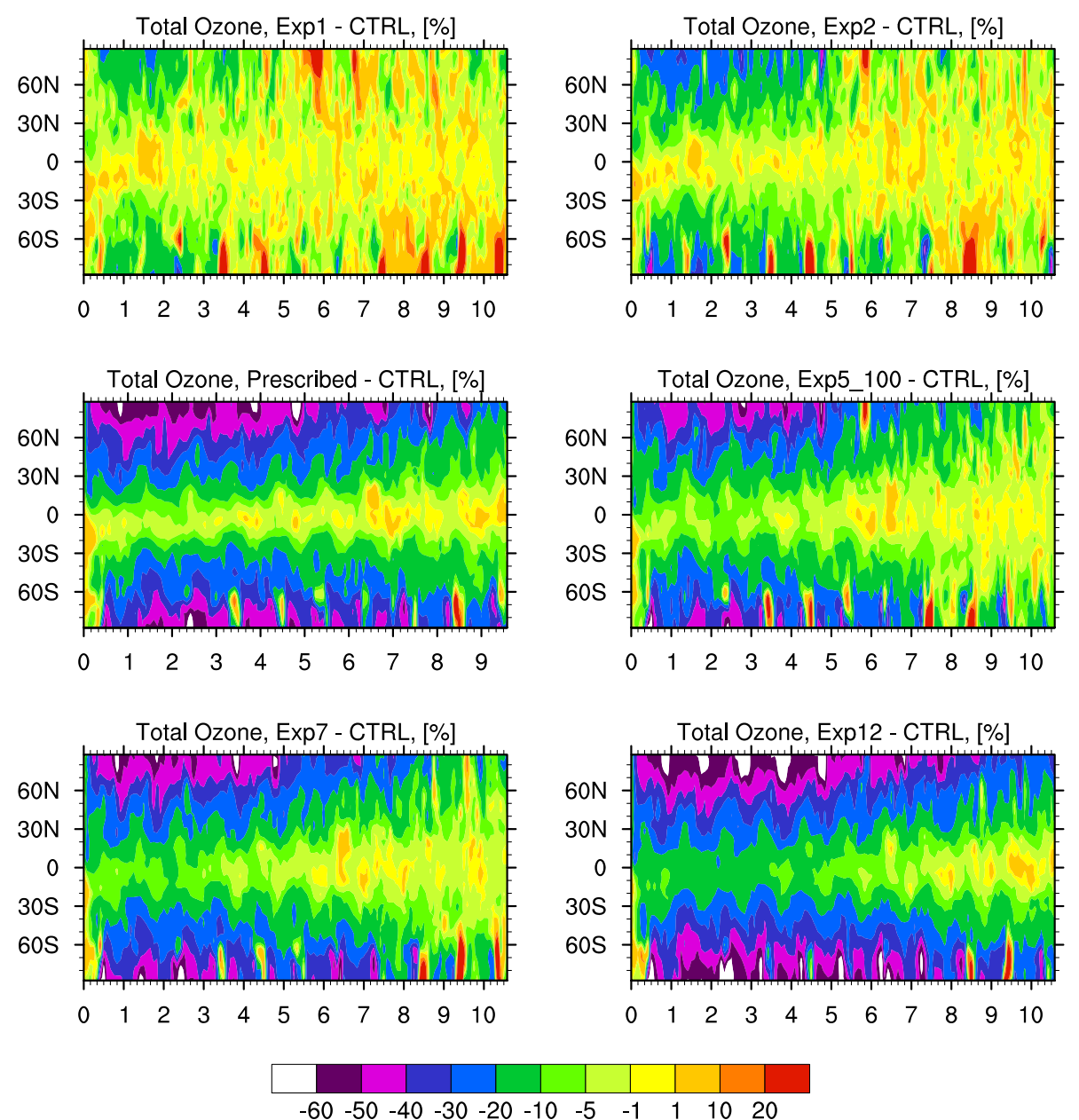

Fig. 13. Zonally averaged total column ozone deviations from the control simulation [\%] as a function of latitude versus time for the simulations Exp1, Exp2, Prescribed, Exp5_100, Exp7, and Exp12.

stratospheric heating and, in general, cooling at the surface. The lower surface temperatures result in reduced precipitation, especially in the tropics. For large tropical volcanic eruptions a winter warming over $\mathrm{NH}$ continents has been observed, which is caused by an enhanced meridional temperature gradient between equator and pole, leading to a strengthening of the polar vortex and a NAO-like circulation pattern. A similar effect is found in our model results for the first two winters after the emission of $1 \mathrm{Tg}$ of soot. Besides the climatic effects both volcanic sulfate aerosol and soot aerosol have the potential to change stratospheric chemistry. The stratospheric warming accelerates catalytic ozone depletion. While sulfate aerosol from volcanic eruptions furthermore provide surfaces for heterogeneous reactions that lead to ozone destruction, this is not the case for soot aerosol. Nevertheless, soot aerosol is much more efficient in depleting ozone due to its stronger heating effect.

Nuclear conflicts remain the greatest immediate threat to the health and welfare of human mankind, not only to the people of the conflicting nations, but to the whole globe (Ruff and Helfand, 2012). As discussed by previous studies the climatic consequences of a nuclear war, that is, cold, dark and dry environmental conditions as well as increased UV radiation at the earth's surface, could cause massive reductions in agricultural production due to shorter growing seasons and delayed maturation of crops, resulting in mass starvation for most of the world's population, especially in an era of increasing globalisation of markets (Harwell and Hutchinson, 1986). Besides the disruption of food supplies, people would suffer from many other threats like high levels of radioactive contamination, enhanced UV radiation, psychological stress, epidemics, and the lack of medical care (Robock, 2010). Therefore, concerted political efforts are necessary to agree on a complete nuclear disarmament and to abolish this existential threat caused by nuclear weapons. 


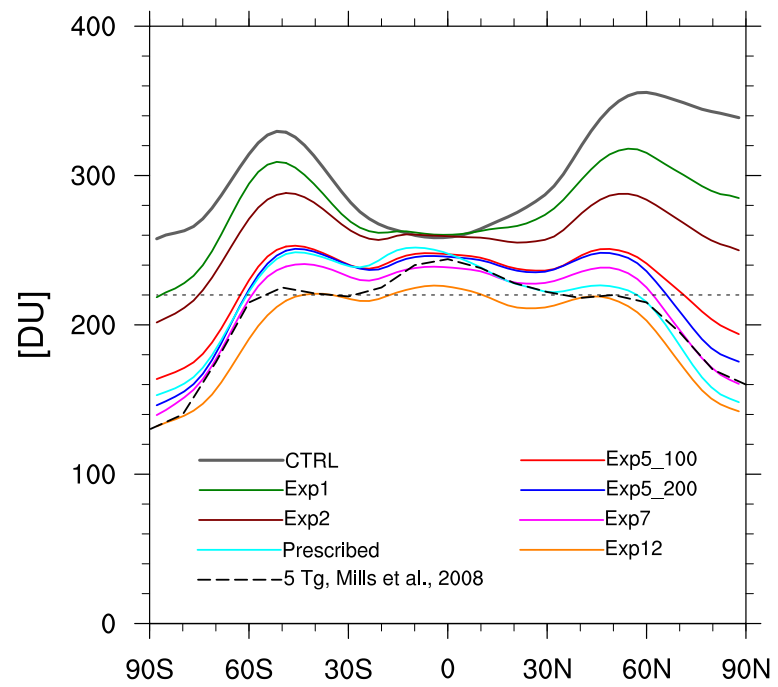

Fig. 14. Zonal mean total column ozone column [DU] averaged over the second year following the nuclear war as a function of geographical latitude for the CTRL simulation (grey) and the soot simulations (color code see legend). The dashed black line shows results by Mills et al. (2008, their Fig. 3). The dotted line indicates ozone hole conditions (220 DU).

Acknowledgements. This research was funded by the Task Force on Nuclear Disarmament and Non-Proliferation of the Swiss Federal Department of Foreign Affairs. C. Hoyle was also partially funded by SNF grant number 200021_140663. We thank E. Egger (Swiss Federal Office for Civil Protection, BABS), P. Sidhu (Geneva Centre for Security Policy, GCSP), E. J. Jensen from NASA Ames, and A. Robock (Rutgers University) for helpful discussions concerning the uncertainties of the soot emission scenarios. M. J. Mills (NCAR) is acknowledged for kindly providing the 4-dimensional soot and temperature distribution from the WACCM3 model and for helpful discussion.

Edited by: A. Geer

\section{References}

Anchukaitis, K., Buckley, B., Cook, E., Cook, B., D’Arrigo, R., and Ammann, C.: Influence of volcanic eruptions on the climate of the asian monsoon region, Geophys. Res. Lett., 37, L22703, doi:10.1029/2010GL044843, 2010.

Auchmann, R., Brönnimann, S., Breda, L., Bühler, M., Spadin, R., and Stickler, A.: Extreme climate, not extreme weather: the summer of 1816 in Geneva, Switzerland, Clim. Past, 8, 325-335, doi:10.5194/cp-8-325-2012, 2012.

Brohan, P., Ward, C., Willetts, G., Wilkinson, C., Allan, R., and Wheeler, D.: Arctic marine climate of the early nineteenth century, Clim. Past, 6, 315-324, doi:10.5194/cp-6-315-2010, 2010.

Catchpole, A. J. W. and Faurer, M.-A.: Ships' Log-Books, Sea Ice and the Cold Summer of 1816 in Hudson Bay and Its Approaches, Arctic, 38, 121-128, 1985.

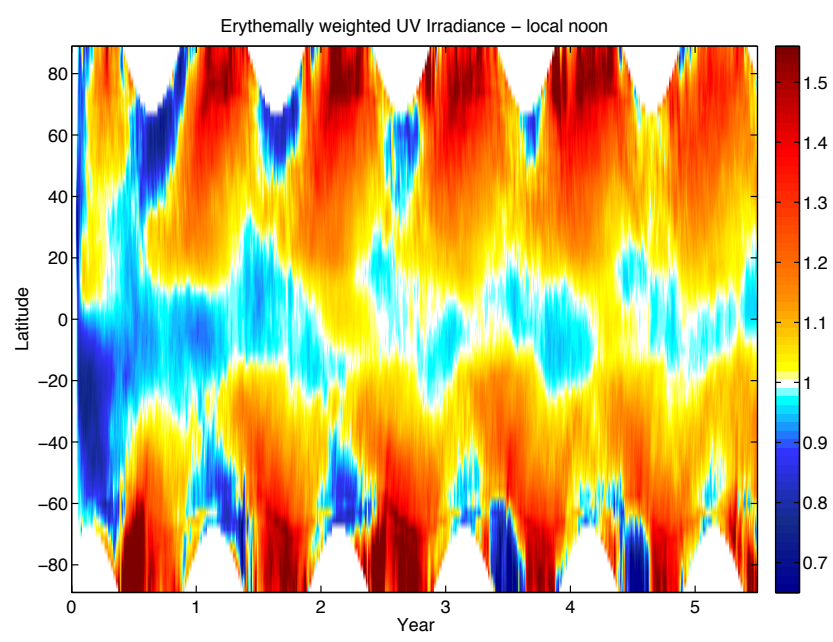

Fig. 15. The zonally averaged ratio between the erythemally weighted UV irradiance at local noon for Exp5_100 and the CTRL run, for the first $5 \mathrm{yr}$ of the model run. No data is available during the polar night when the sun is below the horizon.

CCMVal, S.: SPARC CCMVal Report on the Evaluation of Chemistry-Climate Models, SPARC Report No. 5, WCRP-132, WMO/TD-No. 1526, 2010.

Chang, J. S., Brost, R. A., Isaksen, I. S. A., Madronich, S., Middleton, P., Stockwell, W. R., and Walcek, C. J.: A ThreeDimensional Eulerian Acid Deposition Model: Physical Concepts and Formulation, J. Geophys. Res., 92, 14681-14700, 1987.

Douglass, A., Fioletov, V., Godin-Beekmann, S., Müller, R., Stolarski, R. S., Webb, A., Arola, A., Burkholder, J. B., Burrows, J. P., Chipperfield, M. P., Cordero, R., David, C., den Outer, P. N., Diaz, S. B., Flynn, L. E., Hegglin, M., Herman, J. R., Huck, P., Janjai, S., Jánosi, I. M., Krzyścin, J. W., Liu, Y., Logan, J., Matthes, K., McKenzie, R. L., Muthama, N. J., Petropavlovskikh, I., Pitts, M., Ramachandran, S., Rex, M., Salawitch, R. J., Sinnhuber, B.-M., Staehelin, J., Strahan, S., Tourpali, K., Valverde-Canossa, J., and Vigouroux, C.: Stratospheric Ozone and Surface Ultraviolet Radiation, Chapter 2 in Scientific Assessment of Ozone Depletion: 2011, Global Ozone Research and Monitoring Project-Report No. 52, 516 pp., World Meteorological Organization, Geneva, Switzerland, 2011.

Fischer, E., Luterbacher, J., Zorita, E., Tett, S., Casty, C., and Wanner, H.: European climate response to tropical volcanic eruptions over the last half millennium, Geophys. Res. Lett., 34, L05707, doi:10.1029/2006GL027992, 2007.

Fromm, M., Bevilacqua, R., Servranckx, R., Rosen, J., Thayer, J. P., Herman, J., and Larko, D.: Pyro-cumulonimbus injection of smoke to the stratosphere: Observations and impact of a super blowup in northwestern Canada on 3-4 August 1998, J. Geophys. Res., 110, D08205, doi:10.1029/2004JD005350, 2005.

Hamilton, K.: Early Canadian Weather Observers and the "Year Without a Summer”, B. Am. Meteor. Soc., 67, 524-532, 1986.

Harwell, M. A. and Hutchinson, T. C. (Eds.): Environmental Consequences of Nuclear War, SCOPE 28. Volume II - Ecological and Agricultural Effects, New York, John Wiley \& Sons, 1986. 
Hess, M., Koepke, P., and Schult, I.: Optical Properties of Aerosols and clouds: The software package OPAC, B. Am. Meteor. Soc., 79, 831-844, 1998.

Holick, M. F.: Vitamin D: importance in the prevention of cancers, type 1 diabetes, heart disease, and osteoporosis, Am. J. Clin. Nutr., 79, 362-371, 2004.

Joseph, R. and Zeng, N.: Seasonally modulated tropical drought induced by volcanic aerosol, J. Climate, 24, 2045-2060, 2011.

Lin, S. and Rood, R.: Multidimensional flux-form semi-Lagrangian transport schemes, Mon. Weather Rev., 124, 2046-2070, 1996.

Manzini, E., Giorgetta, M. A., Esch, M., Kornblueh, L., and Roeckner, E.: The influence of sea surface temperatures on the northern winter stratosphere: Ensemble simulations with the MAECHAM5 model, J. Climate, 19, 3863-3881, 2006.

Mayer, B. and Kylling, A.: Technical note: The libRadtran software package for radiative transfer calculations - description and examples of use, Atmos. Chem. Phys., 5, 1855-1877, doi:10.5194/acp-5-1855-2005, 2005.

Miller, G. H., Geirsdottir, A., Zhong, Y., Larsen, D. J., OttoBliesner, B. L., Holland, M. M., Bailey, D. A., Refsnider, K. A., Lehmann, S. J., Southon, J. R., Anderson, C., Björnsson, H., and Thordarson, T.: Abrupt onset of the Little Ice Age triggered by volcanism and sustained sea-ice/ocean feedbacks, Geophys. Res. Lett., 39, L02708, doi:10.1029/2011GL050168, 2012.

Mills, M. J., Toon, O. B., Turco, R. P., Kinnison, D. E., and Garcia, R. R.: Massive global ozone loss predicted following regional nuclear conflict, P. Natl. Acad. Sci. USA, 105, 5307-5312, doi:10.1073/pnas.0710058105, 2008.

Post, J. D.: A study in meteorological and trade cycle history: The economic crisis following the Napoleonic Wars, J. Econ. History, 34, 315-349, 1974.

Robock, A.: Volcanic eruptions and climate, Rev. Geophys., 38, 191-219, 2000.

Robock, A.: Nuclear winter, WIREs Clim. Change, 1, 418-427, 2010.

Robock, A., Oman, L., and Stenchikov, G. L.: Nuclear winter revisited with a modern climate model and current nuclear arsenals: Still catastrophic consequences, J. Geophys. Res., 112, D13107, doi:10.1029/2006JD008235, 2007a.

Robock, A., Oman, L., Stenchikov, G. L., Toon, O. B., Bardeen, C., and Turco, R. P.: Climatic consequences of regional nuclear conflicts, Atmos. Chem. Phys., 7, 2003-2012, doi:10.5194/acp7-2003-2007, 2007b.

Roeckner, E., Brokopf, R., Esch, M., Giorgetta, M., Hagemann, S., Kornblueh, L., Manzini, E., Schlese, U., and Schulzweida, U.: Sensitivity of simulated climate to horizontal and vertical resolution in the ECHAM5 atmosphere model, J. Climate, 19, 37713791, 2006.
Rozanov, E., Zubov, V., Schlesinger, M., Yang, F., and Andronova, N.: The UIUC three-dimensional stratospheric chemical transport model: Description and evaluation of the simulated source gases and ozone, J. Geophys. Res., 104, 11755-11781, 1999.

Ruff, T. and Helfand, I.: Humanitarian and public health efforts are needed to eradicate nuclear weapons, ANZJPH, 36, 303-307, 2012.

Stenchikov, G. L., Delworth, T. L., Ramaswamy, V., Stouffer, R. J., Wittenberg, A., and Zeng, F.: Volcanic signals in oceans, J. Geophys. Res., 114, D16104, doi:10.1029/2008JD011673, 2009.

Stenke, A., Schraner, M., Rozanov, E., Egorova, T., Luo, B., and Peter, T.: The SOCOL version 3.0 chemistry-climate model: description, evaluation, and implications from an advanced transport algorithm, Geosci. Model Dev., 6, 1407-1427, doi:10.5194/gmd-6-1407-2013, 2013.

Steppuhn, A., Micheels, A., Geiger, G., and Mosbrugger, V.: Reconstructing the Late Miocene climate and oceanic heat flux using the AGCM ECHAM4 coupled to a mixed-layer ocean model with adjusted flux correction, Palaeogeogr. Palaeocl., 238, 399423, doi:10.1016/j.palaeo.2006.03.037, 2006.

Toon, O. B., Turco, R. P., Robock, A., Bardeen, C., Oman, L., and Stenchikov, G. L.: Atmospheric effects and societal consequences of regional scale nuclear conflicts and acts of individual nuclear terrorism, Atmos. Chem. Phys., 7, 1973-2002, doi:10.5194/acp-7-1973-2007, 2007.

Trigo, R. M., Vaquero, J. M., Alcoforado, M. J., Barriendos, M., Taborda, J., Garcia-Herera, R., and Luterbacher, J.: Iberia in 1816, the year without a summer, Int. J. Climatol., 29, 99-115, 2009.

Turco, R. P., Toon, O. B., Ackerman, T. P., Pollack, J. B., and Sagan, C.: Climate and smoke: An appraisal of Nuclear Winter, Science, 247, 166-176, 1990.

Vogelmann, A. M., Ackerman, T. P., and Turco, R. P.: Enhancements in biologically effective ultraviolet-radiation following volcanic-eruptions, Nature, 359, 47-49, 1992.

Webb, A. R. and Engelson, O.: Calculated Ultraviolet Exposure Levels for a Healthy Vitamin D Status, Photochem. Photobiol., 82, 1697-1703, 2006.

Xia, L. and Robock, A.: Impacts of a nuclear war in South Asia on rice production in Mainland China, Clim. Change, 116, 357-372, 2013. 